\title{
ETHOS "EMERGENTE": AS PESSOAS, AS PALLARAS E AS COISAS
}

\author{
Diana Nogueira de Oliveira Lima \\ Universidade Federal do Rio de Janeiro - Brasil
}

Resumo: O presente artigo reflete sobre o modo como alguns segmentos da "elite" do Rio de Janeiro vêm se servindo dos elementos do universo mercantil para fazerem valer um novo critério classificatório na sociedade brasileira. Com base em análise de material de imprensa sobre a rede de relações carioca conhecida como a "Nova Sociedade Emergente", o argumento central é o de que está em jogo nesse processo de identificação social um ethos que valoriza, concomitantemente, o trabalho árduo e o consumo conspícuo. Tal ethos passou a ser característico de alguns meios sociais a partir de um momento recente de transição na história político-econômica do país. Identifico no jornalismo social o surgimento e funcionamento de um sistema discursivo feito de imagens e notícias que associam sujeitos "bem-sucedidos" ao consumo de bens de alto custo, e que, desde a "abertura dos mercados", na década de 1990, positiva o binômio trabalho/êxito material, fornecendo sustentação simbólica a esse recurso classificatório.

Palavras-chave: consumo, jornalismo social, sucesso, trabalho.

Abstract: This article is an ethnographic study of the ways whereby some sectors of Rio de Janeiro's elites have been playing a key role in shaping the consumption universe and, therefore, creating new classification criteria of the Brazilian society. Using newspaper evidence on the network of relations known as "The New Emerging Society" and direct observation of those elites' life style, my main hypothesis is that those elites share attitudes and a type of mentality that concomitantly cultivate the work ethics and conspicuous consumption. Such attitudes and mentality have become defining features of certain social groups at a given moment in the country's recent political-economic history. Finally, based on evidence culled from the press media, I endeavor to identify the birth and functioning of a discursive system that sanctions the positive value placed on the binomial work ethics and material success, and, relying on the very notion of success, symbolically upholds this classification system.

Keywords: consumption, press media, success, work. 
O emergente é hoje um símbolo do sucesso. Não importa de onde você veio - de Cascadura ou de Bonsucesso, ${ }^{1}$ importa onde você está. Não adianta vir da Suíça e ir sabe Deus aonde - melhor nem citar o nome do lugar. O importante é estar bem com o seu sucesso. Os conceitos sobre emergência mudaram muito. O importante agora é ser qualificado como "produtivo", seja você tradicional ou emergente. Se você é tradicional e não produz, não será nada. Da mesma forma, se você é emergente, não pode parar de emergir!

Vera Loyola (ícone “emergente”), Jornal do Brasil, 1994

\section{Introduç̃o}

A “Nova Sociedade Emergente” apareceu pela primeira vez no Caderno Ela, do jornal O Globo, na edição do sábado, 24 de julho de 1994. Batizada pela colunista social Hildegard Angel, numa referência explicitamente inversa ao empobrecimento daquela que era ali tratada como "Tradicional Sociedade Carioca”, essa rede de relações - que tem como motivo central de articulação entre seus integrantes o alcance recente de um elevado poder aquisitivo ganhou, por seis anos, a atenção constante da imprensa carioca bem como da mídia impressa de circulação nacional.

Entre 1994 e 2000 os "emergentes da Barra" estiveram em pauta com freqüência quase diária no jornalismo social, para muito além do jornal O Globo. Carros importados, mansões cinematográficas e roupas de marca eram os itens mais destacados por esse segmento jornalístico cuja pujança se verifica, com facilidade, nas bancas de jornal ou nas ante-salas dos serviços privados de saúde e de beleza, para perfilar os "emergentes” e retratar seu estilo de vida. O estereótipo da "emergente", 2 sedimentado por revistas como Caras, Quem, Chiques e Famosos ou Contigo, por colunas sociais diárias e também no imaginário do senso comum de numerosos segmentos sociais do Rio de Janeiro, é uma mulher loira de cabelos lisos (cor e textura desenvolvidos quimica-

1 Cascadura e Bonsucesso são bairros do subúrbio do Rio de Janeiro.

2 Embora a “emergência” não seja, em absoluto, um fenômeno particularmente ou exclusivamente feminino, grande parte do discurso a seu respeito gira em torno das mulheres “emergentes”.

Horizontes Antropológicos, Porto Alegre, ano 13, n. 28, p. 175-202, jul./dez. 2007 
mente), que tem a pele do rosto tratada com recursos de dermatologia estética e o corpo moldado por uma lipoaspiração, e mantido na academia de ginástica sob a orientação de um personal trainer. Ela está permanentemente enfeitada com grifes, jóias e brilhos de um modo geral. É uma “empresária”, “batalhadora”, casada com um empreendedor de “sucesso". Residente na Barra da Tijuca, ${ }^{3}$ a “emergente” está sempre dirigindo um último tipo importado e vive, entre um shopping center e outro, a consumir grifes nacionais ou, de preferência, estrangeiras.

No período em que os “emergentes” vão merecer o entusiasmo do colunismo social, as camadas médias estão sendo atingidas não apenas em seu poder de compra, mas sendo, sobretudo, submetidas a uma acentuada ferida simbólica. Em decorrência da “crise econômica” que se armara nos anos 1980, logo após o boom de consumo registrado precisamente no ano de 1980, e que adentrava pela década de $1990,{ }^{4}$ muitos advogados, engenheiros e economistas ficaram repentinamente desempregados, sendo obrigados a dirigir vans, assumir cargos de vendedores ou outras soluções de subsistência consideradas menores segundo os valores e a régua de prestígio desse estrato social (Velho, 1987, p. 39-54; 1998). Em contrapartida, tomado de empréstimo do vocabulário

3 A Barra da Tijuca começa a crescer na década de 1970. Inicialmente, sua ocupação obedece às diretrizes prescritas pelo plano-piloto do arquiteto modernista Lúcio Costa. Na década de 1980, em favor de um "maior aproveitamento relativo" do espaço, o modelo original de paisagem urbana sofreu reformulação substantiva. Hoje a Barra é feita de pistas de alta velocidade, grandes shopping centers, condomínios murados, outdoors e redes de restaurantes. Essa região, de arranjo muito divergente ao da Zona Sul da cidade - onde, desde a década de 1960, as camadas médias e altas cariocas concentram moradia -, é majoritariamente habitada pela ascensão social. Segundo a palavra nativa, trata-se da "Miami brasileira”.

4 Para Marcelo Néri (2002), “metropolitan unemployment crisis” é a fórmula mais apropriada para nomear os acontecimentos econômicos que ocorreram na segunda metade da década de 1990, quando as taxas de desemprego cresceram em mais de um terço do número inicial (subindo de 4,7 milhões de desempregados para 7,2 milhões nas áreas metropolitanas) e quando também foi principalmente atingida a remuneração salarial dos segmentos médios e altos da sociedade, residentes nos grandes centros urbanos. De acordo com esse mesmo autor, embora o tamanho da população pobre ou muito pobre do país seja de 29,3\%, formando um total importante de 46 milhões de pessoas, surpreendentemente, nesse intervalo de tempo, a pobreza não aumentou. Evidentemente, ele não desconsidera a desigualdade social que caracteriza o Brasil. Muito ao contrário, chama atenção para o fato de que, em 1999, na sociedade brasileira "the richer $10 \%$ detain[ed] nearly $50 \%$ of the national income. On the other hand, the poorer 50\% appropriate[d] $10 \%$ of national income. That is, individual income of the richer group[was] nearly 25 times than that of the poorer group.” (Néri, 2002, p. 54).

Horizontes Antropológicos, Porto Alegre, ano 13, n. 28, p. 175-202, jul./dez. 2007 
utilizado pelos economistas para falar das economias em ascensão, o termo “emergente”, quando empregado na coluna social, premiava os "bem-sucedidos” com um especial sabor de vitória, pois vinha metaforizar os históricos anseios de uma brasilidade promissora. Suas "trajetórias de sucesso" - um contraste com as condições econômicas mais abrangentes - eram abordadas como paradigmáticas das expectativas formuladas sobre este país, que, segundo dizeres especializados, se dirigia a uma posição finalmente gloriosa na arena do capitalismo mundial. Simultaneamente, como que em uma inesperada relação metonímica para com as projeções de integração da economia brasileira no mercado global, não apenas se dizia que as sacolas de compras "emergentes” contêm as mais consagradas grifes internacionais como essas pessoas, repetidamente convidadas a falarem sobre si mesmas em entrevistas na mídia impressa, afirmavam freqüentar com assiduidade e desenvoltura as avenidas de compras mundiais.

Para examinar em sua peculiaridade o fato social "os emergentes” e tendo em mente a força performativa das palavras (Bourdieu, 1982) e o poder fundador das categorias de classificação (Foucault, 1966, Hacking, 2002) compreender o que o diferencia daquele conhecido personagem da modernidade, o novo-rico, é imprescindível situá-los no contexto de seu surgimento. Desse modo, é forçoso notar que essa rede social que teve sua ascensão amplamente reportada como resultado de seu trabalho empreendedor na Zona Norte e nos subúrbios da cidade do Rio de Janeiro apareceu no colunismo social precisamente na época em que, com vistas ao combate à "crise econômica”, o Brasil fazia "abertura comercial e financeira” e a "privatização".

Em um ambiente de $80 \%$ de inflação mensal e longa estagnação econômica, em março de 1990 foi empossado no país o primeiro presidente eleito pelo voto direto após 29 anos. Endossando as recomendações aos países periféricos para a retomada do crescimento econômico, para o desenvolvimento e para o alcance da igualdade social que tiveram "Consenso [em] Washington”, Collor tratou de cumprir uma de suas promessas eleitorais, colocando em prática profundas reformas estruturais. Assim, pôs-se a diminuir a presença do Estado na arena econômica, tomou suas medidas para a estabilização da moeda e implementou, no país, a "abertura comercial”.

No interior das grandes organizações, algumas delas criadas pela “privatização”, em benefício da "eficiência” foram adotados programas agressivos de corte de pessoal e, em muitos casos, definida uma nova política salarial. Em nome da "gestão participativa”, os profissionais que sobreviveram a 
esses programas foram submetidos ao esquema de salário variável. Isso significa que desde a segunda metade da década de 1990, a remuneração total passou a se dividir em duas partes: uma parcela fixa e outra variável em função de resultados individuais, departamentais e da própria empresa como um todo. Trabalhar muito, "dar resultado" e por isso ser bonificado com participações nos lucros, passou a ser a lógica imperante em muitos contextos oganizacionais. Enquanto para alguns profissionais todo esse esquema é uma distorção que provoca infelicidade e que, permanentemente, os ameaça de desemprego, para outros, trata-se de um grande estímulo ao seu "espírito empreendedor”. Não custa lembrar que o "espírito empreendedor" se manifestou ainda, embora com diferentes contornos, entre os profissionais que, atingidos pelos cortes de pessoal, optaram por ou dispuseram dos recursos financeiros necessários para tomar o caminho do "próprio negócio".

Foi na esteira dessas mudanças que categorias caras ao ideário neoliberal - tais como "eficiência”, "empreendedorismo”, "gestão participativa”, "resultado", "bônus”, “competitividade”, "produtividade”, etc. - penetraram a vida econômica brasileira. Contudo, uma vez que a economia não é uma esfera apartada da dinâmica coletiva, é escusado dizer que a incorporação dessas noções não repercutiu apenas nas práticas econômicas. Neste artigo, vou examinar informações etnográficas sobre o fenômeno "Nova Sociedade Emergente” para demonstrar de que maneira elas ressoaram também nas percepções sobre as relações entre os sujeitos sociais, e entre esses e os objetos, atribuindo novos sentidos às práticas identificadas com o trabalho, com a manipulação do dinheiro e com o consumo.

\section{As palavras}

Na imprensa brasileira, o jornalismo econômico cresceu e ganhou prestígio durante o regime militar. Ao mesmo tempo em que reprimia a liberdade de expressão em assuntos políticos, o governo estimulava o noticiário econômico, onde eram divulgadas as conquistas e avanços que o legitimava perante a sociedade. Assim, os jornais foram levados a substituir o noticiário político pelo econômico e por notícias internacionais, e as editorias de economia, que tinham antes um lugar secundário, ampliaram seu espaço, atendendo a um público de tomadores de decisão, tecnocratas e formadores de opinião (Abreu, 2003, p. 13-74). 
Com a redemocratização, os jornalistas da área continuaram a desfrutar de grande prestígio nas redações. Porém o perfil atual da imprensa econômica é mais técnico e muito menos engajado do que durante o regime militar, quando os jornais tinham em seus quadros artistas, escritores, professores universitários e jornalistas, motivados à profissão por razões políticas e que, em muitos casos, apesar da censura, conseguiam fazer do jornal um instrumento de contestação. Em sua pesquisa, Abreu (2003) constata que muitos jornalistas engajados nas décadas de 1970 e 1980 têm agora uma atitude antimilitante, em nome de uma atuação mais profissional. Segundo alguns jornalistas por ela entrevistados, ironicamente, hoje, quando o país vive um momento de plena liberdade de imprensa, há um desinteresse crescente por temas políticos. Os "leitores ou telespectadores têm interesse cada vez maior pelo noticiário jornalístico utilitário; o público se interessa por aquilo que pode usar, busca informações que possam lhe trazer algum ganho direto e imediato” (Abreu, 2003, p. 68).

Os cadernos diários contam com a participação de economistas e têm agora em torno de seis páginas. Eles divulgam as notícias econômicas do dia, informações sobre empresas e instituições governamentais, notas, entrevistas, cotações das bolsas e de moedas estrangeiras, instruções sobre aplicações e colunas analíticas. Fazendo par com esses cadernos diários, há os jornais integralmente dedicados aos assuntos econômicos, como a Gazeta Mercantil e o Valor, as diversas publicações e periódicos que incorporam a linguagem do management e cobrem assuntos relativos às variáveis do mercado, e os manuais de "auto-ajuda", que prometem fornecer a uma legião de leitores aderentes à lógica mercantil os ensinamentos necessários ao "sucesso" (Boltanski; Chiapello, 1999).

Ao mesmo tempo em que, contribuindo para o assentamento da representação de que o problema da (e a solução para a) sociedade brasileira é meramente econômico (Souza, 2003, p. 93-188), se mantém central o debate jornalístico sobre a economia, avulta, paralelamente, o segmento da mídia impressa especialmente focado na exposição do mundo dos indivíduos que, apesar da crise continuada, conseguiram ter "sucesso". Novas colunas sociais, além das já existentes, são criadas nos informativos diários e inúmeros semanários voltados ao retrato da vida dos “bem-sucedidos” são lançados nesse momento. É também nessa mesma década de 1990 que a notícia sobre as minúcias da intimidade amplia seu espaço em revistas e jornais mais sérios, tais como os semanários Veja e Isto É, em geral sob as rubricas Gente ou Comportamento.

Horizontes Antropológicos, Porto Alegre, ano 13, n. 28, p. 175-202, jul./dez. 2007 
No início da investigação, ainda restrita à leitura e à coleta do material impresso diariamente publicado sobre os “emergentes”, fui conduzida pelo próprio exercício de levantamento desse material a perceber que não era apenas a mídia que tinha sempre muito a dizer a respeito dos "emergentes”. Quando comentava sobre minha pesquisa, às vezes tão somente para pedir licença para recortar uma página de revista a uma recepcionista de consultório médico ou de salão de cabeleireiro, era imediato o infalível interesse que ela suscitava. Entre pessoas próximas - arquitetos, psicanalistas, economistas, engenheiros, pedagogas, médicos -, relacionamentos mais ou menos estreitos que trago da infância em um colégio particular, habitantes da Zona Sul do Rio de Janeiro, ${ }^{5}$ a notícia sobre meu trabalho de campo correu em uma velocidade notável. E da mesma forma como acontecia com as recepcionistas, a manifestação da vontade de saber (e de se pronunciar) sobre os dados que vinha apurando sobre "aquela gente [é] absurda”, "pessoas vazias”, "pessoas que não passam daquilo mesmo”, "pessoas que consomem só por consumir”, "que não têm educação”, "pessoas que não têm berço”, "que adoram aparecer” era automática. Não demorei a compreender que esse conjunto de reações ao meu objeto não poderia escapar ao meu caderno de campo. Mais do que isso, a insistência com que periodicamente essas pessoas próximas voltavam ao assunto buscando novidades e reafirmando sua posição pejorativa aos modos materiais "emergentes” logo me convocaram à observação paralela de sua própria pauta de consumo. Afinal, quem eram aqueles sujeitos sociais para quem, do outro lado da cidade, reina uma falta de gosto sobre a qual é preciso se colocar e voltar a se colocar? Estava claro que o fato social “emergentes da Barra” não se constituía apenas de pessoas que se portam de um jeito ou de outro. O intenso palavrório a seu respeito era igualmente parte do fenômeno que buscava explicar.

Foi assim que incorporei à análise o mundo capitalista que transcorre nas ruas mais "privilegiadas" da cidade, por onde, assim como entre os "emergentes”, também são consumidos produtos para a aparência, grifes nacionais e internacionais, carros importados, etc. Os sinais etnográficos registrados desse modo talvez um tanto flutuante remeteram ao importante questionamento sobre a validade explicativa dos dizeres separatistas que encontrei - evidente-

\footnotetext{
5 Refiro-me a pessoas que nasceram, foram educadas, residem, trabalham, se divertem e educam seus filhos nos bairros da cidade ocupados pelas camadas médias e altas desde, pelo menos, a década de 1950.
}

Horizontes Antropológicos, Porto Alegre, ano 13, n. 28, p. 175-202, jul./dez. 2007 
mente, sem perder a dimensão da diferença de estatuto que as afasta - na mídia e nas conversas à minha volta, bem como na teoria sobre fronteiras de status (cf. Bourdieu, 1979). De maneira muito geral, todas essas palavras concordam que alguns atores sociais, nesse caso específico, os “emergentes”, porque não foram socializados no código adequado, não foram educados em contato com a arte e não aprenderam a ter uma aproximação estética ao mundo jamais poderão pertencer à verdadeira "elite". De acordo com o jornalismo social e com todos aqueles que não apenas leram o jornalismo social, mas incorporaram seu vocabulário ao cotidiano, eles, e especificamente eles, como não têm nem educação e nem berço, investem somente e de maneira conspícua em estética corporal, em grandes marcas, em decoração, em carros importados, em festanças. Será, porém, verdade que os “emergentes” estão sozinhos no consumo conspícuos desses bens? Ainda, para pensar comparativamente e esboçar a questão em termos veblenianos (Veblen, 1998), qual é para eles o lugar simbólico desse consumo? Os “emergentes” têm algum interesse em, no tempo ocioso, investir na interioridade, aprimorar seu espírito e substituir o consumo conspícuo por outras formas de explicitação de seu prestígio? Eles querem, desse modo, distinguir-se definitivamente de quem não dispõe de seu tempo para o cultivo de si pois precisa trabalhar arduamente para sustentar um certo padrão de vida?

Por dois anos (entre 1998 e 2000) armazenei e examinei colunas sociais e matérias publicadas sob a rubrica Sociedade nos meios de comunicação impressos de alcance nacional - prioritariamente no jornal $O$ Globo, na revista Veja e na revista Caras. $^{6}$ Nesse período fiz também algumas entrevistas exploratórias. Em 2002, finalmente, comecei a conviver e a ouvir as palavras dos próprios integrantes da "Nova Sociedade Emergente". O arquiteto e decorador Éder Meneghine - uma espécie de emblema midiático da Barra da Tijuca, de quem, em função do enorme falatório carioca sobre "os emergentes”, consegui me aproximar desde que me coloquei as primeiras interrogações e com quem mantive contato durante quatro anos - me apresentou a um dos sócios de um portal eletrônico voltado para assuntos de interesse no bairro.

\footnotetext{
6 A coleta de material impresso envolveu também a recuperação de material de arquivo. Foi assim que consegui copiar as colunas sociais de $O$ Globo desde 1994 e, para efeitos de comparação, algumas peças do jornalismo social das décadas de 1960, 1970 e 1980.
}

Horizontes Antropológicos, Porto Alegre, ano 13, n. 28, p. 175-202, jul./dez. 2007 
Esse pequeno empresário barra-tijucano de aproximadamente 45 anos simpatizou com minha pesquisa. Ele nasceu na Zona Sul e estava na Barra havia dez anos. Mudou-se para lá com a família depois que, em decorrência de uma crise de estresse, pediu demissão da empresa onde trabalhava. Jorge também tinha suas impressões sobre os "emergentes" e para que pudesse verificar, eu mesma, como "eles adoram aparecer", me tomou como colaboradora de um dos fotógrafos de seu site para me introduzir no circuito do society local. Assim, ao mesmo tempo em que continuava a me manter "por dentro" como leitora do colunismo social de veículos nacionais, pude estar também nos eventos sociais dos “emergentes”, ao lado dos responsáveis pelas páginas eletrônicas. Por três meses freqüentei festas, inaugurações, desfiles beneficentes e também situações prosaicas que, segundo o julgamento da equipe, mereciam ter a cobertura do portal. À medida que fui sendo incorporada por aquele meio, fui entendendo que a coluna social produzida no interior da socialidade "emergente" - ou seja, as palavras divulgadas pelo site em que colaborei assim como as que são veiculas em todas as outras colunas de outros jornais da região ${ }^{7}$ - é amplamente valorizada, constituindo o eixo dos encontros. Nessas ocasiões, todos querem ser motivo de comentário e de fotografia para exibição nas páginas locais, homens e mulheres, sendo que ninguém parece considerar aquele espaço de exposição como de menor importância ou "brega". Ao contrário, no evento seguinte é comum ouvir sobre as fotos mais antigas, sendo que há quem reclame e "exija” maior visibilidade dessa vez. O fato de na época da etnografia já não serem, como o foram durante seis anos, assunto privilegiado nos canais de grande circulação não era para eles um problema ou um motivo de ressentimento e em nada abalava sua vontade de posar para uma foto que iria ser apreciada apenas entre eles mesmos. Da mesma forma, jamais me passaram inibição diante da opinião, consensual no meu círculo pessoal de cariocas educados da Zona Sul, de que são "peruas”, "loiras”, “adoram aparecer". ${ }^{8}$ Em todos esses jornais as colunas sociais estampam metade das edições e são comentadas por diferentes "colunistas” do bairro, cujos artigos jamais fazem avaliações sobre a adequação ao "gosto” prescrito para quem aspira à condição de “elite”.

\footnotetext{
No período em que estive no campo verifiquei a existência de seis jornais locais. Como não visitei todos os condomínios e clubes, tenho certeza de que não tive acesso a todos os jornais circulantes na Barra.

${ }^{8}$ Assim como, na Zona Sul, "todo mundo sabe" o que acontece na Barra, na Barra da Tijuca "todo mundo sabe" o que a Zona Sul pensa da Barra.
}

Horizontes Antropológicos, Porto Alegre, ano 13, n. 28, p. 175-202, jul./dez. 2007 


\section{As coisas}

Historicamente, as representações ocidentais sobre o dinheiro e sobre o trabalho são repletas de ambigüidades. De acordo com Dumont (1985, p. 1140), nas sociedades tradicionais, em geral, a riqueza fundiária se distingue claramente dos bens móveis. Para a aristocracia tradicional européia, além da glória militar, a virtude e a honra advinham da capacidade masculina de reproduzir a integridade familiar e manter o patrimônio material (fundamentalmente a terra) de sua linhagem. Até o século XVIII, julgada menor pelo ethos cavalheiresco, a manipulação direta do dinheiro era relegada à burguesia comerciante. Sua disposição para o trabalho empresarial sistemático e para a utilização racional do capital como um fim em si mesmo, uma "vocação" sabemos, ocorria das características peculiares à ética protestante ascética que lhe significava a existência e lhe dirigia a conduta secular (cf. Weber, 1987).

Com a revolução moderna - que dissocia a riqueza fundiária do poder político e estabelece o econômico como esfera independente, de suprema importância para a consolidação da ideologia individualista no Ocidente -, ao mesmo tempo em que se firma o fenômeno da sociedade norte-americana, também na Europa setentrional, onde a legitimidade da aristocracia vai desaparecendo de maneira acelerada, um novo modelo de "valor" passa a ser cultivado. No contexto do "liberalismo" que domina o século XIX e se estende até as primeiras três décadas do século XX (cf. Polanyi, 1957), a riqueza autônoma, produto do "mérito" (mercantil) individual, surge como elemento de distinção no universo do Homo economicus. Porém, no interior desse mesmo ambiente histórico, fazendo oposição às concepções economicistas de progresso, se desenha, sob a forma de denúncia dos males causados por uma civilização que se concentra em aperfeiçoar objetos, colocando em risco a "subjective culture" (Simmel, 1971), uma importante bifurcação na mentalidade ocidental. Desse modo, na sociedade moderna, convivem o mérito burguês que, apoiado nas noções de liberdade e igualdade, associa positivamente trabalho e resultado prático (sendo o dinheiro uma de suas medidas), e a concepção romântica de valor, para a qual sensibilidade e educação de si (Bildung) estão acima de tudo. A fórmula aristocracia intelectual - neologismo inglês significativo do deslocamento que transfere o valor positivo para uma posição supostamente antiburguesa - é expressiva da luta dos artistas e intelectuais românticos contra os filisteus, ou seja, aqueles que renunciam ao espírito em nome do "vil metal”. A qualidade do valor trabalho esbarra ainda em um outro obstáculo: 
apesar da perda de sua supremacia, o velho espírito aristocrático (ou, pelo menos, a sua memória) continua circulando nas sociedades, invadindo inclusive as formações americanas. ${ }^{9}$ Entre a honra aristocrática e a distinção romântica desenvolve-se, assim, um processo complexo de deslizamentos que faz da superposição do trabalho com o dinheiro algo inadmissível. Mesmo no interior da burguesia, observa-se, como é o caso na emblemática família Buddenbrook, com o passar das gerações que o valor do aperfeiçoamento da subjetividade vai sendo incorporado ao estilo de vida das famílias e promovendo um paulatino afastamento dos valores mais imediatos da matéria. A ênfase no trabalho bruto, meramente comercial, e na luta impessoal pela fortuna como valor em si vai sendo assim transformada por uma necessidade romântica de singularização, de modo que os critérios da realização pessoal, da criatividade e da autenticidade passam a assumir papel decisivo nas escolhas ocupacionais. Nesse processo, a profissão vai deixando de ser apenas um meio de vida para ser também, e sobretudo, um campo para a expressão e o desenvolvimento individual.

A descrição que Velho (1998, p. 27) oferece do ethos dominante entre seus "nobres" é elucidativa dos dilemas convencionalmente vividos pelos filhos e netos dos estratos sociais médios e altos:

A disponibilidade financeira era muito valorizada, especialmente se não provinha de um trabalho considerado excessivamente "careta”... Delineia-se, assim, logo de saída, uma possível contradição... Para poder "curtir” as coisas boas da vida é fundamental ter dinheiro, mas, entre essas coisas boas, uma das mais essenciais é não ter horário fixo, trabalhar no que realmente se gosta, não estar "burocratizado" etc.

Permanentemente imersos na difícil tarefa de compatibilizar a manutenção de um padrão de vida que responda às necessidades de sua alma “aristocratizada” com a atitude de recusa e mesmo de desprezo pelo enquadramento exigido no emprego estável, essas pessoas viviam uma vida atravessada de sentidos por vezes antagônicos. Não era apenas o dinheiro ou a

\footnotetext{
9 A mordacidade com que Sinclair Lewis (1980) discorre sobre Babbit e seu mundo não deixam dúvidas sobre a existência de ressalvas ao tipo "business man” também na história dos Estados Unidos. Muito mais recentemente, a prosa ácida de Jonathan Franzen, vencedor do National Book Award de 2001, revisita o tema da distinção na sociedade norte-americana.
}

Horizontes Antropológicos, Porto Alegre, ano 13, n. 28, p. 175-202, jul./dez. 2007 
proveniência "careta" desse dinheiro o que incomodava. Para esse grupo a legitimidade do próprio "sucesso" - mesmo que advindo de uma atividade intelectual ou artística - tinha seus limites. "O sucesso fácil, a aceitação unânime, o aplauso geral poderiam ser encarados com uma certa reserva"; se ele se tornava "contínuo e praticamente ininterrupto" (Velho, 1998, p. 30), passava a ser comprometedor. Pois não se tratava apenas de não se render aos mandamentos burocratizantes do mercado mais convencional de trabalho, mas de se imprimir ao que se fazia uma marca autoral reveladora de uma interioridade elaborada e, portanto, inovadora.

Não causa surpresa, destarte, que no princípio de sua carreira midiática, muitas vezes, o estilo de vida estridente que caracteriza a "emergência" fosse alvo de controvérsia por parte de jornalistas e leitores provenientes das camadas médias e altas do Rio de Janeiro. Denúncias enfáticas do "mau gosto" e da suposta falta de educação das novas freqüentadoras dos salões cariocas, além de reportagens condenatórias da ostentação praticada na Barra da Tijuca conviviam com a flutuação valorativa - entre o elogio ao "sucesso" e o deboche à ostentação - empregada especificamente pela colunista Hildegard Angel para descrever os gestos dessas mulheres para quem a afluência era uma novidade.

As duas colunas abaixo, comentários sobre eventos do high society publicados no Caderno Ela, bem como a chamada de uma matéria na revista Veja, são ilustrativos do tom inicialmente adotado para tratar da relação dos "emergentes" com as coisas.

Em 3 de setembro de 1994, Hildegard Angel escreve:

A Nova Sociedade Emergente e a Antiga Sociedade reunidas pela primeira vez, no mesmo ambiente, em franca confraternização. [...] Um mix de tradição com dinheiro novo, novíssimo. O rico emergente, vocês sabem, é aquele rico positivo, que gasta, faz o dinheiro girar, estimula a produção. É o rico que ainda não alcançou aquele estágio de apatia de quem está acostumado a ter muito dinheiro. Ele gasta com excitação, contentamento, como uma criança quando ganha brinquedo novo. É o rico feliz por ser rico. É o rico em franca pujança e estímulo para ficar mais rico, ampliar seus domínios e seus poderes, é aquele que está somando suas empresas e transformando-as em holdings. E a rica da Nova Sociedade Emergente é aquela rica simpática, natural, sem as distorções que, com o tempo corre-se o risco de sofrer, por excesso de dinheiro. Como, por exemplo, perda de espontaneidade. E a rica recebe com prazer, decora suas novas casas, vive pela primeira vez essa experiência, e com total entusiasmo. Pode, vez em quando, resvalar na inexperiência, mas leva vantagem grande numa maneira de ser desprendida, transparente. Seu

Horizontes Antropológicos, Porto Alegre, ano 13, n. 28, p. 175-202, jul./dez. 2007 
lado naif, em vez de subtrair, creiam, acrescenta. As duas sociedades se complementam, um intercâmbio entre elas só pode resultar positivo. A rica antiga tem muito a transmitir, exemplos e experiências. A rica emergente, além de ter o que aprender, é generosa, atenta, aberta às novidades...

Na semana seguinte, em 10 de setembro, ela retorna com mais informações:

Nos 50 anos de Lobo Lobato, a NSE somou-se a nomes da Sociedade Brasileira de Helena Gondim. Não faltaram banqueiros... A NSE está com tudo!... O party foi das 5 h da tarde de sábado às 5 h da manhã de domingo... Recebiam no deck lindas havaianas, seios nus, requebrando hula-hula e distribuindo colares floridos... balcão com ostras geladas e taças de champagne idem... Um seaquarium com criações de lagostas, peixes, polvos, tartarugas, estrelas do mar... Vaivém de helicópteros... De repente, um grupo de drag queens vestidas de Marilyn em vermelho... Todos com big ovelha pink estampada na $t$-shirt. A do Lobato era preta, com Lobo Mau estampado - afinal, ele chegava à idade do lobo! Bolo era réplica de ilha de nudismo... Toalhas de mesa em onça ou zebradas, até o chão uma visão.

A revista Veja de 10 de janeiro de 1996 sentencia: “A limousine dos ares, os grã-finos do Rio de Janeiro usam o helicóptero como arma contra seqüestro e objeto número 1 de exibicionismo".

Em uma terceira fase da etnografia, continuei a acompanhar a coluna social, mas, levando em consideração os importantes investimentos na aparência física feitos por aquelas pessoas (bem como a representação de que são particularmente ligados à aparência) e seguindo sugestão de mais de uma informante, no início de novembro de 2002, passei a freqüentar a filial Barra de uma importante academia de ginástica. O primeiro contato de pesquisadora da diferença com aquele ambiente foi, no entanto, paralisante. Suas dimensões são realmente inéditas, mas os serviços que oferece, os equipamentos, as modalidades de treinamento, as logomarcas que por ali transitam, a excitação diante da precisão fornecida pela modernidade eletrônica de aparelhos importados, o tipo de música, nada disso me provocou qualquer "choque". É certo que a maior parte das muitas outras academias de ginástica espalhadas pelo Rio de Janeiro são menos confortáveis e menos abrangentes, mas no conceito e na atitude do público, elas são todas muito semelhantes.

Antes de estar no campo, propriamente, a explicação para a subversão das formas convencionais de ser "elite”, por parte dos "emergentes”, parecia 
simples: Em vez de discretos e cultivados, eles são ostensivos e, ao que se diz, se dedicam muito mais à exterioridade e à aparência do que à interioridade. Em suma, não diferem em nada da primeira geração de todas as famílias ascendentes produzidas pela modernidade. O tempo mostrará, porém, que seus filhos e netos (assim como os descendentes de tantos outros novos-ricos que os antecederam) acabarão por internalizar os valores e os modos mais sofisticados que a via natural da educação, e conseqüentemente do contato com as artes e as humanidades, suscitam nas linhagens de extração burguesa. Com os anos, o deslumbramento diante das possibilidades aquisitivas ficará para trás e o cultivo de si ganhará maior espaço em sua existência, tornando-os mais elaborados e polidos e menos conspícuos.

Não obstante, a interação etnográfica e a atenção aos seus hábitos de consumo permitiram verificar, através da mídia e na experiência direta, que passadas duas, às vezes três ou quatro décadas desde a ascensão de uma família e depois de dez anos de existência pública, os filhos e, em alguns casos, netos insistem no comportamento e mantêm o mesmo estilo de vida que fez a fama desses empreendedores da Zona Oeste do Rio de Janeiro: carros importados, corpos “malhados”, resorts, desfile de grifes, festas, filmes do grande circuito, best-sellers e auto-ajuda e, sobretudo, exposição na mídia. Ao mesmo tempo, a ampliação do escopo do trabalho de campo, ou seja, a já mencionada inclusão em minha agenda de pesquisa da observação da pauta de consumo daqueles outros sujeitos sociais provenientes dos estratos médios e altos do Rio de Janeiro, bem como o registro de suas falas sobre as preferências dos “emergentes" aportou-me um dado importante: o repertório de bens materiais que consagrou os "emergentes", assim como as aparições na mídia, as festas, a academia de ginástica como ponto de socialização, a dermatologia estética, etc., não lhes são tão exclusivos. Durante os anos em que, em estado etnográfico, prestei atenção a pessoas próximas, educadas em contextos familiares socioeconomicamente abastados há várias gerações, me deparei com alguns jovens que - fazendo forte contraste com o que se esperaria, por exemplo, de indivíduos educados pelos "nobres" estudados por Velho (1998) na década de 1970 - explicitavam sem cerimônia ter sido o dinheiro o critério prioritário para a sua definição profissional. E também não foi raro encontrar pessoas que, simultaneamente, apontam os "emergentes" como outros com base no gosto e na "futilidade" e reservam uma parcela importante da semana à freqüência à academia de ginástica e ao salão de beleza e consomem todo tipo de produto de grife. A espera de mais uma hora por uma mesa em um restaurante "badala- 
do”, em pé, sobre um salto alto, numa rua de Ipanema, ${ }^{10}$ não é vivenciada como algo desconfortável. Ver e ser visto é parte do programa. Já quanto às cadeiras do Teatro Municipal, ouvi de Alice - filha de um advogado importante, uma mulher cosmopolita e trilíngüe que cresceu, assim como sua mãe, em um colégio católico tradicional e é hoje arquiteta - serem duras demais e portanto "impossível ficar sentada ouvindo Nelson Freire depois de dez minutos."

O cenário que investigava revelou-se então muito mais complexo do que o esperado em função de dois aspectos: de um lado, o desejo por bens de alto custo, material e simbolicamente fabricados pelo capitalismo, não se manifesta apenas entre os "emergentes da Barra"; de outro, ainda assim, o "consumismo" e a "vontade de aparecer" dos "emergentes" anima uma intensa troca de palavras - de admiração ${ }^{11}$ e de repúdio - na sociedade do Rio de Janeiro.

\section{Novas palavras sobre as coisas}

Com o tempo, porém, a forma de fazer-lhes referência, a eles e a outros "batalhadores" de "sucesso", se transforma de maneira patente e o termo "emergente" bem como o fenômeno da ascensão social vão sendo progressivamente ressignficados pela mídia impressa. Uma olhada em alguns exemplares dessa publicação mais folheada do que propriamente lida, a Caras, é o suficiente para se perceber a euforia com que se propõe a retratar um estilo de vida supostamente glamoroso. Os "bem-sucedidos" monitorados por esse segmento da imprensa que se estabelece ${ }^{12}$ na segunda metade da década de 1990 estão sempre sorridentes. Eles são invariavelmente mostrados em situações de festa, de glória e de lazer, que acontecem em residências ou arredores ricamente decorados, ou em viagens para destinos distantes e luxuosos. Vestidos de maneira dispendiosa e no desfrute de suas "conquistas", é assim que sua "vitória” vem sendo reiteradamente evidenciada em tiragem nacional.

${ }^{10}$ Suponho que o alcance da canção Garota de Ipanema me dispense da necessidade de situar simbolicamente esse bairro do Rio de Janeiro.

${ }^{11}$ Já mencionei que escutei mulheres das camadas populares - recepcionistas e também profissionais de serviços de beleza. É fundamental esclarecer, contudo, que alguma admiração pelos “emergentes” pode aparecer em alguns espaços sociais da "elite”, em determinados momentos.

12 Já que estamos falando de consumo, não custa dizer que um produto (nesse caso um segmento editorial) só se estabelece no mercado se há consumidores nele interessados.

Horizontes Antropológicos, Porto Alegre, ano 13, n. 28, p. 175-202, jul./dez. 2007 
Nessa sociedade eternamente à espera do "desenvolvimento", em tempos de “economia de mercado”, é inequívoca, na imprensa, a autoridade atribuída aos esquemas de pensamento e aos valores do individualismo de mercado, próprios a uma concepção singular de "dever ser" da economia. Com o passar da década de 1990, a idéia de que o "sucesso" - corolário de riqueza material e celebridade - está ao alcance de todos os indivíduos que dispuserem de iniciativa, espírito empreendedor, coragem e perseverança para trabalhar competitivamente, irrompe ostensivamente nos periódicos, conotada com grande positividade.

\section{As pessoas?}

Ao longo de seus dez anos de notoriedade, os “emergentes” ficaram largamente conhecidos, favorável ou desfavoravelmente, em função de seus hábitos de consumo. Durante a pesquisa, bastava uma rápida alusão ao trabalho em meus círculos informais de sociabilidade e pessoas as mais variadas se antecipavam com algum comentário sobre as práticas materiais dos "emergentes da Barra”.

Contudo, um exame mais detido do conteúdo apurado no jornalismo social bem como das minhas anotações de campo indicam que os bens de alto custo são valorizados em diversos meios sociais. Seu uso conspícuo, obediente a outras regras que não as do "gosto" e da "distinção" (cf. Bourdieu, 1979), extrapola em muito as fronteiras da Barra da Tijuca. Indo além, seria uma imprevidência não considerar que os integrantes da rede social a partir da qual comecei a refletir não estão sozinhos nas consecutivas edições desse nicho editorial. Ao contrário, ali têm sido exibidos tipos sociais de múltiplas origens socioeconômicas, cumpridoras de carreiras profissionais muito díspares, sendo umas mais recentes e outras mais antigas.

Um pequeno fragmento da diversidade exposta na mídia impressa desde a segunda metade da década de 1990 faz ilustração oportuna de que quero dizer:

Paulo Tarso faz 70 anos, festa reúne vips e políticos na capital federal. Mais uma vez, Lúcia Flecha de Lima (63) confirmou sua fama de ótima anfitriã. A comemoração dos 70 anos de seu marido, ex-embaixador Paulo Tarso Flecha de Lima, se tornou uma noite memorável para os cerca de 800 convidados que compareceram à mansão do casal no Lago Sul... Como presidente da Comissão das Relações Exteriores do Senado, tinha de felicitar uma das figuras de maior relevância na diplomacia 
brasileira, acrescentou Suplicy... A empresa de Belo Horizonte utilizou cerca de 400 orquídeas variadas, mais de mil velas, sous plats indianos e mesas antigas sobre tapetes persas, que recobriam o jardim da residência dos Flecha de Lima. (Caras, 18 de agosto de 2003).

Mais discreto nas palavras do que nas imagens, o texto da Caras, é plausível objetar, não acrescenta nada de particularmente novo sobre o estilo de vida das elites, não raro detentoras de alto poder aquisitivo (a não ser pelo fato de terem trocado a discrição pelo estardalhaço do colunismo social). Não obstante, as duas páginas duplas de fotos de corpo inteiro e mais algumas com imagens em plano médio, principal atrativo dessa revista, ao mostrarem o embaixador soprando sua vela de aniversário apoiada sobre um bolo em formato de "nádegas femininas”, reclamam questionamento.

Foi apenas na Vogue que encontrei a explanação da anfitriã da festa sobre o formato pouco usual do bolo retratado na primeira revista: na matéria, Lúcia Flecha de Lima revela para a sociedade de onde veio sua idéia de preparar para a festa dos 70 anos de seu marido um bolo como esse. Na reportagem da Vogue ${ }^{13}$ Lúcia Flecha de Lima afirma que essa é a parte do corpo da mulher preferida por seu marido e que, assim sendo, ela achou que a data era uma boa oportunidade para homenageá-lo com essa "surpresa".

Dessa sorte, nas colunas e na interação etnográfica, verifico que os atributos e os produtos envolvidos na caracterização do tipo social "emergente", como já argumentei anteriormente (Lima, 2004, 2005, no prelo), não são, em si, especificidade dessa rede social que tão longamente animou os meios impressos de comunicação, nos anos 1990. A observação etnográfica dos hábitos de consumo de outros grupos da elite econômica do Rio de Janeiro - uma medida que me pareceu imprescindível para uma hermenêutica mais acurada do fenômeno "emergente" quando realizava a pesquisa de longo curso que fundamenta essa argumentação - revela que os itens constantes na cesta de compras daquelas pessoas para quem, reiteradamente, os “emergentes” são outros e não mais do que (im)puro assunto para as futilidades da coluna social, não

\footnotetext{
${ }^{13}$ Infelizmente, apesar de tê-lo lido, não tenho comigo esse número da publicação, o que me impede de reproduzir com fidelidade seu texto. De qualquer maneira, diante de tão inédita explicação (ineditismo relativo não apenas à explicação, mas ao fato da presença de um bolo como esse nas mais altas rodas da diplomacia nacional), minha memória registrou uma síntese do que ela dizia.
}

Horizontes Antropológicos, Porto Alegre, ano 13, n. 28, p. 175-202, jul./dez. 2007 
diferem em muito daqueles adotados pelos próprios “emergentes”. Tampouco lhes são específicos os modos de adoção e a economia afetiva que informa suas opções de consumo. Hábitos materiais extravagantes que fazem o estilo de vida dos “emergentes", a mídia noticia e meu trabalho de campo não deixou dúvidas, não são realidade apenas na Barra da Tijuca, embora tenham servido, com freqüência, como mote acusatório em alguns círculos sociais. Em contrapartida, o insistente noticiário sobre esses sujeitos - e toda a extensa fala que, a partir dele, se espalhou por esta sociedade que durante tanto tempo foi receptiva ao comentário sobre os "emergentes” a ponto de incorporar o termo ao seu cotidiano - é, ele sim, um fato social particular que a mim se afigura como importante objeto de interpretação.

\section{Ethos emergente}

A releitura dos dados aponta as pistas para o esclarecimento sobre a fofoca que se instalou na segunda metade da década de 1990. Embora muito menos lembrada, desde o início, uma outra dimensão de sua trajetória foi sublinhada pelo colunismo social para qualificá-los.

Surge, nos domínios e condomínios da Barra da Tijuca, uma nova safra de socialites. Que recebe, freqüenta, viaja e, sobretudo, gasta. E a fina flor desse grupo social emergente vai se reunir na próxima quinta para um happy hour na penthouse do Caesar Park em torno do seu decorador darling, o Éder Meneghine. Entre as 300 novas cabeças coroadas, estarão lá Joana Macedo (o marido é latifundiário urbano na Barra), Tania Pereira (Ourobrás), Ana Borges de Souza (mulher elegante, o marido Janualdo é dono da maior marmoraria do país, a Mardil), Vera Loyola (o marido, Pelino Bastos é sócio da A. C. Lobato), Fátima Mania (Hospital das Clínicas da Barra), Carminha (do Bernard Rajzman), Samira (do[...]), Tania Bueno (dona de Caldas Novas em Goiás). Elegantes e perfumadas. Dariam para encher um novo tomo inteiro do Sociedade Brasileira da Helena Gondim [... ] (Caderno Ela, O Globo, julho de 1994, grifo meu).

Desde o seu surgimento, não é, portanto, apenas sobre o que consomem ou sobre como consomem que a mídia assunta em torno dos “emergentes”. Os "negócios” aos quais se deve sua "emergência” e o esforço "produtivo” neles despendido são também uma fala constante. Essa fala esteve presente, como se pode ver, no texto que lhes deu origem e apareceu também em muitos outros momentos da pesquisa. À questão da "produtividade” o senso comum não de- 
vota a mesma atenção que à "futilidade", ao "exibicionismo" ou ao "consumismo", mas ela é uma constante na mídia, foi uma constante no campo e me ficou flagrante também, diversas vezes, em entrevistas exploratórias. Diferentemente do consumo "ostentatório" ou "fútil”, porém - e creio ser esse o ponto -, o trabalho árduo não é um valor em toda parte. O trabalho árduo não é, certamente, um valor para a classe (ociosa) analisada por Veblen (1998).

Apesar da semelhança entre os ricos cenários e figurinos daqueles a quem, a partir de agora, prefiro chamar - e já explico o porquê - de pessoas identificadas com um "ethos emergente” e os ricos cenários e figurinos daqueles outros indivíduos que incorporei à pesquisa a título de controle, as conversas não giram em todos os casos em torno daquilo que tanto empolga André. Esse meu informante de 22 anos, que conheci na happy hour da academia de ginástica, orgulhosamente se reconhece como "emergente da Barra". Ele começou a trabalhar enquanto cursava a faculdade de administração porque queria "ganhar [a minha] grana” e adora falar sobre sua trajetória:

Meu pai sempre me deu estudo, me deu um carro bom quando eu fiz 18 anos, eu sempre morei bem. Mas o resto, ele disse que eu tinha que me virar. Aí, desde cedo, eu fui me virar. Eu adoro um charuto, um bom vinho, eu sou fascinado por carro. Essa é a terceira empresa que eu tô trabalhando. Eu tive sorte. Bem, eu tive competência também, não foi só sorte. Eles implantaram um sistema novo que veio de fora, e não tinha ninguém que entendia da coisa. Aí eu tava ali, bobinho, eles me deram o manual e mandaram eu me virar... pouco tempo depois, eu, novinho, eu era muito novo, tava dando aula pros caras, tava dando treinamento nas empresas. Minha carreira fez assim ó, vupt. E eu vivo recebendo convite de outras empresas. Às vezes, a gente sai do trabalho lá pelas nove e vai jantar. Acaba sendo uma continuação do trabalho, porque a gente aproveita pra resolver muita coisa, é muita coisa... Eu já trabalhei, uma vez, 36 horas seguidas. Eu adoro... A gente trabalha muito. Eu gosto de trabalhar... Eu me realizo com isso, pô. Claro, eu também adoro o reconhecimento lá de fora. No mundo inteiro, os caras da empresa me conhecem. Eu sou o mais novo no meu cargo. E é um cargo bom. Fim de semana passado eu fui com a minha namorada pr'um hotel na Ilha Grande. Mais de 600 reais a diária... É superexclusivo. São 6 ou 8 suítes só. Não tem nem cardápio, você pode pedir o que quiser. Eu não gosto de me preocupar com preço. Quando eu vou a restaurante, eu não quero ficar preocupado com o preço do prato. Não faz diferença se o prato custa 35, 45 ou 60 reais. Eu não me importo em gastar. Eu trabalho pra cacete... Desde o começo, eu privilegiei o trabalho do que a faculdade, e não me arrependo... Eu só vou sossegar quando eu estiver na presidência da empresa. 
Ainda que de modo fragmentado, creio que o cotejo do depoimento de André com o de um outro rapaz, dessa vez oriundo de uma família antiga das camadas médias-altas, descendente de duas gerações de médicos, leva o raciocínio adiante:

Eu tenho um grande orgulho do que eu estudo e de onde eu estudo, e uma extrema certeza de que escolhi a profissão e a carreira certa. Por meio desta escolha maravilhosa que eu fiz na minha vida as portas do mercado de trabalho, e principalmente do mercado financeiro, se abriram diante do meu horizonte... Hoje eu trabalho num banco de investimento brasileiro, onde até então me satisfaço por completo. Atualmente, onde trabalho, existem em torno de 70 estagiários, e a convivência com cerca de 30 deles é diária e inevitável. É uma característica do banco onde eu trabalho substituir cargos e funções antes executadas pelos funcionários por estagiários... Os funcionários se sentem, a todo o momento, ameaçados pela presença em massa de estagiários que estão ali como uma possível ameaça a seus cargos e empregos. Pro mercado financeiro os estagiários são superimportantes porque sem eles os custos com folha de pagamento iriam aumentar de uma maneira assustadora. Além disso, os estagiários são sangue novo e estão de maneira geral com toda motivação necessária para se dedicar por completo ao mercado. Eu vivo atualmente de 8 a 10 horas do meu dia no estágio... Os valores de salários e participações nos lucros enchem os olhos dos estagiários de ambição. Ambição essa que me impulsiona também.

Sua irmã fez o ensino fundamental e o médio no Colégio de Aplicação da UFRJ e segue os passos da tradição profissional familiar. Esfregando o dedo polegar no indicador, porém, esclarece: "É financeiro. Eu tô indo pela cirurgia estética porque é o que dá grana... tô gostando.”

Entre essas pessoas identificadas com o “ethos emergente”, a explicitação do suor que lhes proporciona o padrão de vida atual é tão insistente quanto os bens de consumo de luxo que sinalizam seu "sucesso". Para ganhar nitidez sobre meu material empírico recorro à comparação. Verifico então que enquanto os "nobres” de Velho (cf. 1998) buscam se afastar dos constrangimentos do trabalho bruto porque eles inibem a criatividade, ou do "sucesso fácil" porque ele contradiz a tão valorizada expressão da autenticidade, os indivíduos aderentes ao "ethos emergente" não só estão totalmente imersos nesse mundo do trabalho burocrático com horário fixo (ou, em um outro sentido, sem horário, uma vez que a maior parte das pessoas "não te[m] hora para sair do trabalho”), como sentem orgulho e fazem questão de relembrar que estão ali e que ali, 
naquele ambiente de muita "batalha", se distinguem como "batalhadores" de "sucesso". Entre si, eles falam de "negócios" e falam do dinheiro que gastam na mesma proporção com que portam os produtos nos quais foi gasto muito dinheiro como uma fala a seu respeito. Obedecendo à mesma lógica utilizada pela mídia para exaltar quem "batalhou”, "venceu” e merece notoriedade, aqueles a quem prefiro me referir como pessoas identificadas com o "ethos emergente" adotam para se pensarem e para se mostrarem na interação com o mundo um código que associa prestigiosamente sucesso no trabalho com dinheiro (e com o consumo que esse dinheiro viabiliza).

Embora tenha encontrado na Barra da Tijuca um grande número de indivíduos que, além de falarem de si através da exposição e preocupação com a (rica) aparência de si são também "batalhadores”, minha preferência pela formulação "ethos emergente" (em vez de "emergentes da Barra") para definir o fenômeno que analiso se deve a três razões. Em primeiro lugar, embora ao ser "lançada" pela mídia a "Nova Sociedade Emergente" (que em pouco tempo, passou a ser conhecida também por um nome - "emergentes da Barra" - que os associa a esse bairro do Rio de Janeiro) fosse efetivamente uma rede social composta de indivíduos residentes na Barra da Tijuca, o tipo social que a investigação tornou aparente não está apenas na Barra. Em segundo lugar, não foram raros os casos em que me defrontei com indivíduos oriundos de famílias estabelecidas (Elias, 2000) - filhos e netos de profissionais qualificados, de empresários de porte variado ou, eventualmente, de artistas e intelectuais - que tiveram uma "boa educação", mas que optaram por uma formação universitária e uma carreira profissional em que a meta era, claramente, enriquecer porque, como ouvi certa vez: "Cultura eu já tenho em casa. Agora eu quero é dinheiro.” Finalmente, no contexto da pesquisa, em especial durante os meses em que convivi na academia de ginástica e dali freqüentei situações sociais ${ }^{14}$ que reuniam seus membros nos finais de semana, estive com sujeitos sociais que já formam a terceira geração de famílias que integram a rede a quem Hildegard Angel, em 1994, deu o nome de "Nova Sociedade Emergente”. Essas pessoas, apesar do passar do tempo, não internalizaram a sofisticação e a discrição que historicamente caracterizam as famílias burguesas (Le Witta, 1988). Ao contrário, o que verifiquei foi a perpetuação transgeracional da ade-

${ }^{14}$ Caminhadas, escaladas, “aulões”, etc. 
rência aos significados e à lógica mercantil que, historicamente, marca a primeira das gerações desse estrato social.

As páginas da mídia aqui em causa se servem com freqüência da noção de "sucesso" como "gancho". Para fundar e legitimar socialmente o que compreende como sucesso, em consonância com o tipo de linguagem adotada pela economia na década de 1990, ela valoriza a "produtividade”, imprime uma marca fortemente favorável à exibição dos "resultados" objetificados em bens de consumo e, introduzindo no senso comum um novo sentido para o jogo de “classement” (cf. Bourdieu, 1979), promove a fórmula trabalho/dinheiro/consumo ostentatório à posição de razão primeira para a divisão do espaço social.

Como que invertendo a simbólica que tradicionalmente ordena a hierarquia social no Ocidente, segundo a qual o "gosto" é o critério para a identificação das fronteiras de status - um gosto que, apurado na educação de si e ao longo de gerações, rejeita a ostentação -, a imprensa vem fazendo o elogio irrestrito ao trinômio trabalho/dinheiro/consumo conspícuo, conferindo-lhe um caráter prestigioso completamente inédito no Ocidente. De maneira independente da atividade adotada para o seu ganho, o dinheiro (e tudo o que o dinheiro pode pagar) é reverenciado por essa categoria jornalística tão sólida e largamente instalada no mercado editorial nacional e por ela premiado com o privilégio da exposição para o reconhecimento público.

Apresenta-se, assim, para um conjunto muito numeroso de leitores um espetáculo em que a "batalha” dos atores é a causa e a "glória”, tangibilizada na riqueza monetária exibida nas próprias matérias ou nos anúncios de bens de luxo que as entremeiam, é o seu efeito. Em tempos de "economia de mercado", enquanto "batalhadores" trabalham em seus por "resultados", a explicitação da afluência material e o consumo conspícuo de bens de alto custo foram perdendo a unanimidade quanto ao seu caráter pejorativo para assumirem um novo lugar simbólico. Se em alguns contextos brasileiros - midiáticos e reais - a categoria "emergente" mantém sua conotação acusatória e a atitude "emergente” (conspícua, indiscreta, deselegante e o que mais) permanece merecendo reticência, em muitos outros contextos os esquemas de pensamento, o vocabulário e os emblemas da "emergência", do trabalhar muito, enriquecer e ostentar, se impõem como versão laicizada da glória e se estabelecem como um conjunto significante forte e de significado identitário favorável. Nesse segundo ambiente, onde o menosprezo histórico dispensado à ascensão social recente não abate os agentes nem os motiva a reverem seus modos de confundirem a carreira profissional produtivista com o sentido de sua vida coberta de bens 
materiais, a estampa do "luxo" opera como artifício retórico: consumir muito e consumir produtos caros é corolário de "sucesso".

Embora não se percebam como tal e muitas vezes façam mesmo parte daquele universo de pessoas que acionam a categoria "emergente" como uma calúnia, a atitude daqueles que partilham o "ethos emergente" em face do trinômio trabalho/dinheiro/consumo conspícuo é muito semelhante à conduta “emergente”. Suas vidas são prioritariamente dedicadas ao trabalho, mas em contraste com o tipo ideal do empreendedor capitalista descrito por Weber, a quem o ascetismo secular do protestantismo proibia o "uso irracional da riqueza”, no tempo vago consomem bens e serviços de alto custo para seu prazer e conforto - que entendem serem refinados e universalmente desejados. Hábitos culturais convencionalmente valorizados por outros segmentos da "elite" e, em especial, pelo grupo estudado por Velho (1998), são muitas vezes tidos como chatos ou como perda de tempo. Me disse Lúcio, morador da Lagoa, consultor independente na área de tecnologia há 20 anos, doutor em Engenharia pela PUC-Rio:

Eu não tenho paciência pra teatro, pra cinema, o único programa que a gente faz, o meu prazer, é comer fora. Durante a semana, não. Durante a semana, eu gosto de chegar em casa e tomar meu whisky, não tenho disposição pra sair. Às vezes, a gente liga pro Quadrifoglio e eles mandam em casa direitinho, tudo arrumadinho, eles mandam até alguém pra servir, se você quiser.

Na mesma ocasião, um jantar na casa de alguém que nos é comum, esse que ouvi como informante me falou também sobre o motivo por que, apesar do prazer pela pesquisa e pela sala de aula, deixou a vida acadêmica:

Quando eu comecei na consultoria, eu conciliava as duas coisas. Eu adoro aquele ambiente... entrei na PUC garoto. Mas não dá... Eu fui sendo mais solicitado, um projeto puxava outro... Como professor, você não tem retorno nenhum.

"Ralar" muito, ter "sucesso" e ser premiado é, como se pode ver, uma lógica que extrapola o mundo da mídia e que ordena a vida de outras pessoas além daquelas que integram a rede de relações conhecida como os "emergentes da Barra”. No período em que a economia brasileira se voltava para a “competição" e para a "competitividade”, em 1994 a "produtividade” e o "sucesso" dos "vencedores" objetificados em bens de consumo extravagantes mereceram os cumprimentos da coluna social do maior jornal do país. Até 
então, para pessoas como "os emergentes da Barra”, os "bem-sucedidos" do mercado e as celebridades do mundo pop, no Brasil e mesmo na sociedade norte-americana analisada por Mills (1975) não havia outro nome: nouveaux riches, e nem outro sentimento: menosprezo. De sua parte, historicamente, uma vez estocados de capital econômico, ansiosos por substituírem o menosprezo por prestígio, esses personagens, através das gerações, cuidavam de acumular capital simbólico. Sobre o conteúdo e a forma desse capital simbólico não havia dúvida. Os caminhos e o tempo gasto para se adquiri-lo podiam variar, mas não muito. Desde então, entretanto, na "elite" da sociedade brasileira contemporânea, outros conteúdos e outras formas vêm recebendo acento distintivo.

\section{0 esforço e não a sorte}

Em seu livro sobre a experiência da fama de atores e atrizes no mundo da moderna sociedade de massas, Maria Cláudia Coelho (1999) encontra subsídio para reflexão em um artigo que discute os resultados de uma pesquisa sobre os ídolos do star system norte-americano. O autor desse artigo identifica que até os anos 1940 do século XX, os meios de comunicação de massa costumavam exibir homens de negócios, os considerados “ídolos da produção”. Desde então, esses personagens cedem lugar aos artistas e atletas (os "ídolos do consumo”). A justificativa para esse fenômeno, fornecida pelo pesquisador citado pelo autor consultado por Coelho (1999, p. 31), é a seguinte:

Atribuindo essa guinada ao desencanto provocado pela percepção de fragilidade do sistema capitalista, desnudado pela quebra da Bolsa em 1929, Lowental assinala o efeito ao mesmo tempo confortador e desorientador da idolatria aos vencedores no mundo do show business. Enfatizando a importância do fator "sorte" (em detrimento do esforço individual que caracteriza a figura do self made man), o star system estimula o sonho de todos - sorte qualquer um pode ter - ao mesmo tempo em que consola os fracassados - é a sorte, e não o empenho ou o talento, que conta.

Não obstante, no universo brasileiro contemporâneo de construção midiática de uma percepção positiva da equação trabalho + $($ dinheiro + consumo $)=$ sucesso, mesmo aqueles artistas que atuam unicamente na televisão e em torno dos quais muitas vezes há uma polêmica sobre seus verdadeiros méritos (talen- 
to ou aparência), são representados como pessoas que "batalham" muito. Meditar, fazer "lipo", fazer duas horas de exercícios físicos em sua academia caseira sob a orientação de um profissional especializado, mudar os cabelos para um papel na novela e manter uma dieta alimentar saudável são práticas descritas como parte de sua agenda de trabalho. Essas pessoas não são sortudas ou apenas belas. Nas páginas desse segmento jornalístico, qualquer um pode ver, e pode ler também, que elas “fazem por onde”. Quando uma dessas pessoas é mostrada em situação de férias, essas férias são, igualmente, justificadas em relação às extenuantes demandas de sua atividade: o fim da novela, o intervalo entre um projeto e outro, um tempo para se recuperar e seguir adiante na carreira.

Desse modo, com o argumento de que a sorte se introduziu no mundo do "sucesso" para apaziguar os que não obtiveram êxito, como ocorreu no star system norte-americano, não é possível explicar o fenômeno que interrogo. As pessoas que aparecem ou que lêem com apetite essas edições da mídia são segundo elas mesmas e segundo a malha discursiva que, desde os anos 1990, ressignificou seu valor social e o significado social de seu dinheiro - muito “consumistas", mas são também muito "trabalhadoras". Por isso - é o que se quer fazer crer - elas têm tudo o que merecem: notoriedade, admiração e fortuna.

\section{Conclusão}

Neste artigo argumentei que o consumo conspícuo de bens de alto custo operado pelos integrantes da rede social conhecida como "Nova Sociedade Emergente" - ou "emergentes da Barra" - não deve ser pensado como um conjunto isolado de práticas e sentidos. Tendo analisado a notícia de alcance nacional suscitada por esse consumo e atentado para a extensa fala que dela se desdobrou pelo Rio de Janeiro, compreendi tratar-se de um dos aspectos de um panorama mais amplo, relativo a um momento recente de transformações histórico-econômicas reportadas pela mídia e vividas pela sociedade brasileira, desde a década de 1990. Para dar conta desse cenário abrangente e complexo, minha etnografia envolveu a atenção e a observação direta de diferentes fontes de produção de significado: o jornalismo social e também o jornalismo econômico (de onde a categoria “emergente” foi tomada de empréstimo), o estilo de vida dos “emergentes”, o conteúdo e a freqüência das muitas palavras pronun- 
ciadas sobre esse outro da "elite" estabelecida (habitante da Zona Sul da cidade) e, finalmente, os próprios hábitos desses que reiteradamente sublinham sua alteridade em relação aos "emergentes".

Com base em uma investigação de longo curso, identifiquei que o fenômeno da "emergência" não se refere somente a uma gente geograficamente localizada - na Barra da Tijuca - e inventada pela mídia, ora objeto de deboche, ora fonte de inspiração. A pesquisa fez ver um jogo mais amplo de identificação social que gira em torno de um ethos que tem o "sucesso" como valor central. Para os sujeitos sociais aderentes a esse ethos, o sucesso é uma articulação de três momentos, todos eles atrelados à lógica mercantil: trabalho empreendedor/ comercial árduo, acúmulo financeiro e consumo conspícuo. Esse ethos, dialética entre práticas e representações acerca de sujeitos e objetos, ganhou legitimidade e progressivamente conquistou a receptividade de diferentes sujeitos sociais, oriundos de variados espaços, ao longo dos anos 1990.

A partir daquele momento, de um lado, a economia brasileira endossou as diretrizes e princípios do "mercado livre” e, de outro, o vocabulário econômico local e internacional, tendo cunhado a categoria "emergente" em substituição à nada simpática categoria "subdesenvolvido”, passou a empregá-la para classificar o Brasil no teatro da economia mundial. Assim, procurei descrever e analisar um tipo social particular que embora seja muito contemporâneo, não me parece ser pura reprodução de um modelo global ou dever-se aos aspectos que constituem aquilo que se considera como pós-modernidade. Há, certamente, no comportamento desse fato social uma transgressão das barreiras entre a alta cultura e a cultura de massas, e das fronteiras entre as personalidades do meio político ou intelectual e do meio pop. O segmento da mídia especializado em retratá-lo aumenta sua tiragem nacional valorizando o consumo de bens materiais, muitos deles produzidos em outra parte do globo e unindo em uma mesma matéria significante pessoas de origens diversas, tradicionalmente mantidas à parte umas das outras por uma questão de "gosto" (Bourdieu, 1979).

Porém, identifico que o "ethos emergente”, para a qual o "sucesso" é um produto do trabalho e não da sorte e que, pude constatar, resiste como força simbólica ao longo de já duas e às vezes três gerações entre os integrantes da rede que inspirou a coluna social de $O$ Globo em 1994, ou nasce na geração que se profissionaliza nos anos 1990, é um fato socialmente fabricado pela recente história do Brasil.

Aqui estiveram, portanto, em causa sujeitos sociais da "elite" que, em tempos de "mercado livre” e nessa sociedade eternamente à espera do desen- 
volvimento, no lugar da histórica aposta no cultivo de si (Bildung) como meio de acesso à distinção, entusiasmada e irrestritamente consideram "sucesso" a resposta financeira originada daquilo que representam como seu esforço, seu empenho, sua dedicação e seu talento para o mercado.

\section{Referências}

ABREU, Alzira Alves de. Jornalistas e jornalismo econômico na transição democrática. In: ABREU, Alzira Alves et al. Mídia e política no Brasil: jornalismo e ficção. Rio de Janeiro: FGV Editora, 2003. p. 13-74.

BOLTANSKI, Luc; CHIAPELLO Ève. Le nouvel esprit du capitalism. Paris: Gallimard, 1999.

BOURDIEU, Pierre. La distinction: critique sociale du jugement. Paris: Minuit, 1979.

BOURDIEU, Pierre. Ce que parler veut dire: l'économie des échanges linguistiques. Paris: Arthème Fayard, 1982.

COELHO, Maria C. A experiência da fama. Rio de Janeiro: Editora FGV, 1999. DUMONT, Louis. Homo Aequalis I: genèse et épanoissement de l'idéologie économique. Paris: Gallimard, 1985.

ELIAS, Norbert; SCOTSON, John L. Os estabelecidos e os outsiders. Rio de Janeiro: Jorge Zahar, 2000.

FOUCAULT, Michel. Les mot et les choses. Une archéologie des sciences humaines. Paris: Éditions Gallimard, 1966.

HACKING, Ian. Making up people. In: HACKING, Ian. Historical Ontology. Harvard University Press, 2002. p. 97-114.

LE WITTA, Béatrix. Ni vue ni connue: approche ethnographique de la culture bourgeoise. Paris: Éditions de la Maison des sciences de l’homme, 1988.

LEWIS, Sinclair. Babbit. São Paulo: Abril Cultural, 1980.

LIMA, Diana N. O. Nova sociedade emergente: consumidores de produtos ou produção discursiva? Cadernos de Campo, São Paulo: Editora da USP, ano 13, n. 12, p. 11-24, 2004. 
LIMA, Diana N. Trabalhar e consumir: o valor do dinheiro em um grupo social emergente. Comunicação apresentada no colóquio Quantificação e Temporalidade: Perspectivas Etnográficas Sobre a Economia, Museu Nacional, Rio de Janeiro, 2005.

LIMA, Diana N. Sujeitos e objetos do "sucesso": uma antropologia do Brasil “emergente”. Rio de Janeiro: Faperj: Garamond, no prelo.

MILLS, C. Wright. A elite do poder. Rio de Janeiro: Zahar, 1975.

NÉRI, Marcelo Cortês. Brazilian macroeconomics with a human face: metropolitan crisis, poverty and social targets. In: ECONOMICS WORKING PAPERS (Ensaios Econômicos da EPGE) 464/ Graduate School of Economics, Getulio Vargas Foundation (Brazil). Rio de Janeiro, 2002. p. 1-61.

POLANYI, Karl. The great transformation: the political and economic origins of our time. Boston: Beacon Press, 1957.

SIMMEL, Georg. Subjective culture. In: SIMMEL, Georg. On individuality and social forms. Chicago: The University of Chicago Press, 1971. p. 227-234.

SOUZA, Jessé. A construção social da subcidadania: para uma sociologia política da modernidade periférica. Belo Horizonte: Editora UFGM; Rio de Janeiro: IUPERJ, 2003.

VEBLEN, Thorstein. The theory of the leisure class. New York: Prometheus Books, 1998.

VELHO, Gilberto. Prestígio e ascensão social: dos limites do individualismo na sociedade brasileira. In: VELHO, Gilberto. Individualismo e cultura. Rio de Janeiro: Jorge Zahar, 1987. p. 39-54.

VELHO, Gilberto. Nobres e anjos: um estudo de tóxicos e hierarquia. Rio de Janeiro: Fundação Getúlio Vargas, 1998.

WEBER, Max. A Ética Protestante e o Espírito do Capitalismo. São Paulo: Livraria Pioneira Editora, 1987. 